\title{
Rare congenital coronary anomaly - unroofed coronary sinus
}

\author{
DARIO ĐUKIĆ1, STEVAN BAJIĆ1, VOJISLAV PAREZANOVIĆ2, STOJISLAV KONJEVIĆ1, BARBARA STANIMIROVIĆ1, VANJA BOBIĆ1 \\ ${ }^{1}$ Children Clinic, University Hospital Clinical Centre, Banja Luka, Bosnia and Herzegovina, \\ ${ }^{2}$ University Children Hospital, Belgrade, Serbia
}

Corresponding author:

Dario Đukić

Children Clinic

University Hospital, Clinical Centre Banja Luka

12 Beba bb, 78000 Banja Luka

Bosnia and Herzegovina

Phone: 0038751342453

E-mail:dazza74d@gmail.com

\section{ABSTRACT}

In this paper we describe a case of an eightmonth-old male infant who was diagnosed with an unroofed coronary sinus (UCS) that unusually presented with desaturation and cyanosis after surgical ventricular septal defect (VSD) closure. The patient was initially diagnosed with congenital heart disease (CHD), perimembranous VSD associated with mild stenosis of pulmonary arteries in early newborn period. Although the patient was regularly monitored by a paediatric cardiologist, and was even hospitalized twice due to deterioration of the initially diagnosed disease and the development of congestive heart failure (CHF) and arrhythmias, the UCS went unnoticed. The disease was unveiled completely after VSD was surgically closed and the patient's condition deteriorated postoperatively with desaturation and cyanosis in the intensive care unit (ICU). On that same day the patient was reoperated on. UCS was closed with a pericardial patch, a persistent left superior vena cava ligated (PLSVC) and the patient successfully recovered. This case is an example that UCS is not only rare but is such an insidious congenital heart disease, often masked with associated heart defects. It should prompt every paediatric cardiologist to perform a careful examination of coronary sinus inflow tract or performance of contrast echocardiography in every suspicious case.

Key words: unroofed coronary sinus, coronary sinus septal defect, postoperative cyanosis, echocardiography

\section{INTRODUCTION}

An unroofed coronary sinus is a rare congenital heart anomaly that diverts the blood flow to the left atrium and further to systemic circulation in the setting of decreased right ventricular compliance due to congenital heart or pulmonary diseases. On one hand this enables oxygen-poor venous blood to reach the left side of the heart causing systemic arterial desaturation. On the other hand it raises the risk of paradoxical embolization and serious neurological complications. The disease is most often associated with a persistent left superior vena cava but also with other congenital heart disorders. Hypoxemia is the cause of cyanosis, fatigue, poor growth, polycythaemia that deteriorates over time and raises the risk of serious, even life threatening complications. In order to minimize the risk of devastating neurological sequelae due to paradoxical embolization, closure of unroofed coronary sinus is recommended. The treatment is surgical, but in recent years an interventional procedure which includes placing a covered stent was reported on with promising results, but it requires a proper selection of patients. Early diagnosis still remains an issue. There are promising results in combining transthoracic and contrast echocardiography for, in most cases accurate, early diagnosis and classification of UCS.

\section{CASE REPORT}

We report on a case of an eight-monthold male infant who was diagnosed with UCS that presented with desaturation and cyanosis but only after surgical closure of VSD.

Patient was initially diagnosed with CHD, $6 \mathrm{~mm}$ wide perimembranous VSD associated with mild stenosis of pulmonary arteries in early newborn period. During the follow-up at the age of two months the patient was put on ACE inhibitor (Captopril) therapy because there were signs of $\mathrm{CHF}$. At the age of four months the referring physician noted poor weight gain and breathing difficulties and raised the dose of Captopril. At the age of six months the patient was admitted to our hospital for symptoms and signs of low cardiac output. At presentation heart rate was 220 beats per minute, $\mathrm{O} 2$ saturation was $95 \%$, weight was $5.9 \mathrm{~kg}$. ECG confirmed supraventricular tachycardia that was successfully converted to sinus rhythm with Amiodaron but still remaining in congestive heart failure state that required additional decongestive therapy. He was put on Lasix, Spironolactone, Captopril and Propranolol. As the patient needed further evaluation he was transferred to cardiac surgery centre at the University Children Hospital in Belgrade. Primary diagnosis was confirmed and the cardiac surgery team concluded that surgical closure of VSD must be performed. However, at that stage the patient was discharged from the hospital with a decongestive and antiarrhythmic therapy and is planned for surgery at age of eight months.

Because of the deterioration of congestive heart failure at the age of seven and half months the patient was readmitted to University children hospital and operated on the following day. The VSD was closed with an autologus pericardial patch, and 
soon after, the patient was taken off bypass. A lower $\mathrm{O} 2$ saturation of $85 \%$ was registered. The patient was transferred to the ICU with a further decrease of $\mathrm{O} 2$ saturation to $70 \%$ at $\mathrm{FiO} 2100 \%$. An echocardiography was performed and UCS with a persistent left superior vena cava was confirmed. The patient was immediately transferred again to the operating room. The defect was closed with an autologus pericardial patch and PLSVC ligated. Postoperatively, $\mathrm{O} 2$ saturation was $100 \%$ and the patient was transferred to the ICU. The patient was extubated five hours postoperatively with $\mathrm{O} 2$ saturation of $98 \%$ on room air and showed no breathing difficulties. Seven days later the patient was discharged and successfully recovered. The follow-up period was uneventful, allowing a decrease of medications.

\section{DISCUSSION}

An unroofed coronary sinus (UCS) or coronary sinus septal defect (CSSD) is a rare $\mathrm{CHD}$, which results in an abnormal communication between the coronary sinus and the left atrium. It is classified as a type of atrial septal defect (ASD). The defect consists of partial or complete unroofing of the coronary sinus. Shunting occurs through the defect in the wall of the coronary sinus on the left atrial side. (1) Coronary sinus ASDs are believed to arise from developmental failure of formation of the wall between the coronary sinus and the left atrium. (2)

Coronary sinus defects are often associated with a PLSVC that drains into the coronary sinus but it may also be associated with complex congenital heart lesions. (2) Based on morphological features, UCS is divided into various types: type I completely UCS with PLSVC; type II completely UCS without PLSVC; type III partially unroofed mid portion of coronary sinus; type IV partially unroofed terminal portion of coronary sinus; type $\mathrm{V}$ unroofed sinus syndrome related to cor triatriatum and ASD.

Right and left ventricular compliances primarily determine the direction and degree of shunting. The degree of atrial level shunting may be altered by the presence of associated cardiac lesions, pulmonary disease or both. (3) Pulmonary stenosis, large ventricular septal defect (VSD), pulmonary vascular disease, right ventricular hypertrophy, and pulmonary parenchymal disease increase the portion of the respiratory cycle with right to left flow and the magnitude of the shunt. Any other process causing right or left atrial enlargement can result in stretching of the UCS and increasing the volume of the shunt.

Isolated UCS usually do not cause clinically significant symptoms in childhood. (4) But as it is most often associated with multiple congenital heart defects the symptoms usually present in infancy. The severity of symptoms is dependent of the magnitude of the shunt. Mild shunts cause mild exercise intolerance, frequent respiratory infections. In case of moderate to severe shunt signs and symptoms like dyspnea, cyanosis, desaturation, paradoxical embolisation, transient ischemic attack, cerebral abscess are likely to occur.

Diagnostic approach includes the following imaging studies: chest radiography, echocardiography, magnetic resonance imaging (MRI). In the study by Xie et al. the diagnostic accuracy of echocardiography for the UCS was 65\% . (5) Cardiac catheterization is generally not needed for diagnosis, but may be necessary to evaluate haemodynamics in complicated cases.

Therapeutic options are pharmacological, in the treatment of heart failure or arrhythmias, and surgical. Surgical closure in childhood is the recommended therapy for UCS. (6) The surgical treatment is complicated by its proximity to the atrioventricular node. (7) There have been reports in recent years of successful closure of UCS with a covered stent. (8)

Isolated coronary sinus ASDs are associated with a low rate of morbidity and mortality. Morbidity and mortality rates are notably increased for most patients with UCS associated with additional congenital heart defects, especially with complex congenital heart disease. (9)

\section{CONCLUSION}

Although patients with UCS may be identified during infancy, the condition is frequently not recognized until childhood. A relatively low diagnostic accuracy of echocardiography for the UCS has been demonstrated. The purpose of this report is to draw attention of the physicians as to how insidious UCS is, often masked with associated heart defects. It should motivate paediatric cardiologists for a careful evaluation of coronary sinus inflow or performance of contrast echocardiography in every suspicious case.

\section{REFERENCES}

1. Huang Xin-Sheng. Partially Unroofed Coronary Sinus. Circulation. October/2007;116(15):e373. [Medline].

2. Foster ED, Baeza OR, Farina MF, Shaher RM. Atrial septal defect associated with drainage of left superior vena cava to left atrium and absence of the coronary sinus. J Thorac Cardiovasc Surg. Nov 1978;76(5):718-20. [Medline].

3. Steele PM, Fuster V, Cohen M, et al. Isolated atrial septal defect with pulmonary vascular obstructive disease--long-term follow-up and prediction of outcome after surgical correction. Circulation. Nov 1987;76(5):1037-42. [Medline].

4. Attenhofer Jost CH, Connolly HM, Danielson GK, Dearani JA, Warnes CA, Jamil Tajik A. Clinical features and surgical outcome in 25 patients with fenestrations of the coronary sinus. Cardiol Young. Dec 2007;17(6):592-600. [Medline].

5. Xie MX, Yang YL, Cheng TO, Wang XF, Li K, Ren PP, Lü Q, Lin H, Li L. Coronary sinus septal defect (unroofed coronary sinus): echocardiographic diagnosis and surgical treatment. Int J Cardiol. 2013 Sep 30;168(2):1258-63.

6. Quaegebeur J, Kirklin JW, Pacifico AD, Bargeron LM Jr. Surgical experience with unroofed coronary sinus. Ann Thorac Surg. May 1979;27(5):418-25. [Medline].

7. Lee ME, Sade RM. Coronary sinus septal defect. Surgical considerations. J Thorac Cardiovasc Surg. Oct 1979;78(4):563-9. [Medline].

8. Torres A, Gersony WM, Hellenbrand W. Closure of unroofed coronary sinus with a covered stent in a symptomatic infant. Catheter 
Cardiovasc Interv. 2007 Nov 1;70(5):745-8. PubMed PMID: 17563096.

9. Van Son JA, Black MD, Haas GS, Falk V, Hambsch J, Onnasch JF, Mohr FW. Extracardiac repair versus intracardiac baffle repair of complex unroofed coronary sinus. Thorac Cardiovasc Surg. 1998 Dec;46(6):371-4. PubMed PMID: 9928862. 